Rev. Latinoam. Psicopat. Fund., IV, 3, 164-170

A travessia do trágico em análise

Mauro Pergaminik Meiches

São Paulo: Casa do Psicólogo, 2000

\title{
Temporalidade rodopiando em simultaneidades contrastantes
}

\author{
Miriam Chnaiderman
}

Mauro P. Meiches é um psicanalista que vem fazendo um percurso não linear: fez Ciências Sociais, começou a pós-graduação em Teatro, teve experiências com o trabalho de ator, bem como um contato encarnado com o que é o fazer teatral. Seu primeiro livro, escrito em co-autoria com Silvia Fernandes (Sobre o trabalho de ator, São Paulo: Perspectiva) é uma pesquisa cuidadosa, realizada por meio de entrevistas buscando a compreensão profunda do que é ser ator. Importantes depoimentos de Rubens Corrêa, Marília Pêra, Antônio Fagundes, entre muitos outros, levam a uma profunda reflexão - é tocante a epígrafe de Paulo Autran no capítulo que trata de "A estilização do ator": "Cada vez mais acho que o ator não pode ser um quadro pintado a óleo, ele tem de ser um espelho e o espelho é mutante por natureza”. Esboça-se já aí um fecundo campo de pesquisa para qualquer psicanalista: o trabalho de ator é necessariamente contestatório de qualquer teoria que pregue a identidade como constituinte da essência do humano. No segundo livro de Mauro P. Meiches, A pulsão espetacular (São Paulo: Escuta), fruto de sua dissertação de mestrado, o trabalho infinito e interminável de José Celso Martinez Corrêa o obriga a repensar o processo de criação. Há uma temporalidade que determina uma impossibilidade de consumar o processo sublimatório, implicando um eterno fazer e refazer, um inacabamento que é marca de singularização do Teatro Oficina. 
Tanto a questão relativa à inexistência de uma identidade como a questão da temporalidade levaram Mauro P. Meiches a se debruçar sobre o trágico no processo psicanalítico.

Indaga-se: "Por que um psicanalista se interessaria pelo trágico, um sentimento do mundo que começou a se formar já há muitos séculos?” E a resposta que encontra está nas tragédias, em que "o percurso de um adestramento" se faz claro. Adestramento das pulsões, passagem do mundo de estranhas forças da natureza para um mundo da cultura, da pólis. Mitos de épocas primevas são ressignificados e re-contados, agora à luz de um momento no qual lei humana e lei divina vivem intenso conflito. Tocante exemplo desse momento é dado por Mauro P. Meiches quando nos conta de que forma Ésquilo transformou as Fúrias/Erínias/Coéforas, deusas de uma ordem antiga que velam sobre os crimes de sangue cometidos em família, em Eumênides. Na parte final da peça As Eumênides há um julgamento que é presidido por Atena e de um lado estão as Fúrias e de outro Apolo - pela primeira vez os cidadãos estão votando pela absolvição ou não de um réu acusado de homicídio. Ocorre o empate e Atena vota a favor de Orestes, rompendo a maldição familiar da qual as Fúrias seriam responsáveis. As Fúrias falam de uma profanação da lei antiga. Atena faz um acordo e convida as Fúrias a permanecerem na cidade ao lado de outros deuses prometendo que serão reverenciadas por todos os cidadãos. Assim é que se transformam nas Eumênides. Fúrias que se tornam Eumênides encarnando o processo de domesticação das pulsões. É a narrativa mítica da aventura vivida pela cultura que luta para se estabelecer.

Não por acaso Freud utilizou-se da tragédia grega para falar do devir humano do bebê - o complexo de Édipo é construído a partir de Édipo Rei de Sófocles. A trama é carregada de desejos contraditórios e de ambivalência afetiva, estabelecendo o nó entre o desejo incestuoso e o desejo parricida.

Assim como Mauro P. Meiches, a partir de Lacan - que trabalhou Antígona para refletir sobre o desejo - vários psicanalistas vêm se debruçando sobre o trágico. Aloysio Quintão Bello de Oliveira, em ensaio publicado pela revista Percurso (ano XI, n ${ }^{\circ}$ 22) - "Ao menos uma Antígona não se matou” - conta que ao buscar identificar quem foi Antígona, defrontou-se com várias. Conta que sua versão mais antiga está em tragédias gregas do século V a.C., "Os sete contra Tebas” de Ésquilo e “Antígona” e “Édipo em Colono” de Sófocles; “As fenícias” e “Antígona” (esta desaparecida) de Eurípedes. São as duas de Sófocles que vão dar a cara para o mito. Assim o resume Aloysio Quintão:

... depois de saber que tinha matado o pai e tido quatro filhos com a própria mãe, o rei Édipo fura seus olhos e abandona seu reino, conduzido por sua filha e irmã Antígona. Ele termina seus dias terrenos no bosque de Colono. Os filhos disputam sua sucessão, enquanto o cunhado Creonte é o rei provisório. Em uma batalha, os dois irmãos matam um ao outro. Creonte determina que não se enterre Polinices, que 
guerreara contra a sua pólis, Tebas. Obedecendo aos preceitos da lei religiosa, Antígona cumpre os rituais fúnebres de seu irmão, em desobediência à lei da cidade. E por isso é condenada a morrer emparedada viva em uma caverna.

Aloysio Quintão faz uma interessante retrospectiva sobre os vários usos feitos da figura de Antígona - a título de curiosidade é interessante o que conta quando, após a Segunda Guerra Mundial, Antígona emprestou seu nome aos rebeldes, anarquistas e amorais. Antígona foi usada tanto pelos colaboracionistas de Pétain para exaltar a tradição, família, quanto pelos resistentes ao governo legal imposto pelos alemães. As identificações se multiplicam em posições antagônicas. Aloysio mostra como a ambigüidade está no direcionamento do desejo mesmo de Antígona; refere-se então à sua fala: “...por não me ter tocado em sorte os esponsais nem a criação de filhos, esta infeliz abandonada pelos amigos, ainda viva para o sepulcro”... “espero, porém, confiadamente, que ao chegar serei bem-vinda, para meu pai, querida para ti, minha mãe, e cara a ti, meu irmão. Pois quando morreste, pelas minhas mãos vos lavei e adornei; e agora, Polinices, por ter dado sepultura a teu corpo, obtenho esta recompensa...” Antígona deseja o Belo Bem Supremo, com pai, mãe, irmão, anseia o Paraíso dos gregos, é rebelde, mas quer uma recompensa no além. Aloysio pontua: “para ela viver é ceder e morrer é viver”. Aloysio lembra que Freud chamou sua filha Anna de “minha Antígona” - seria seu sustentáculo fora de sua pólis Viena, caminhando para a morte. Depois, lembra Lacan que, segundo Patrick Guyomard, também tem duas posições distintas. Em $O$ seminário. Livro VII. A ética da psicanálise, Antígona é uma heroína pronta para o sacrifício, para a morte em defesa do seu desejo puro. Já no tempo de "Kant com Sade” e de $O$ seminário. Livro XI. Os quatro conceitos fundamentais da psicanálise, Lacan está impressionado com o se levar o desejo puro até suas últimas conseqüências - após uma rememoração da terrível ascensão do nazismo e de sacrifício ao deus obscuro, e após uma menção aos campos de concentração e ao Holocausto, chegou ao lugar do analista, à sua responsabilidade na história e perante o desenfrear mortífero do gozo. Aloysio faz uma apologia bem justificada do quanto é importante não se identificar com esta Antígona do desejo puro.

Maria Inês França, no seu livro Psicanálise, estética e ética do desejo (São Paulo: Perspectiva), a partir de Lacan, teoriza sobre a dimensão trágica do desejo.

Gláucia Dunley, no seu ensaio “O silêncio da Acrópole” publicado na mesma revista Percurso, relata seu trabalho sobre o trágico em Freud: “o superego como agenciador das relações trágicas entre sujeito e cultura”. Gláucia cita abundantemente o ensaio de Hölderlin, Reflexões, no qual é articulada a modernidade a um tempo trágico em que se deu a retração do divino ou a "retirada categórica dos deuses”. Gláucia relata que, para Hölderlin, a dimensão do trágico é a ferida que separa o humano do divino. Propõe, a partir daí, a sublimação como um gozo trágico, distinta do gozo edípico. Em outro ensaio de Hölderlin citado por Gláucia 
Dunley, Fundamento a Empédocles, de 1799, assumindo a tarefa de aprofundar o conceito de trágico, afirma que o poema trágico fica tensionado entre dois pólos: "o excesso de intensidade e o excesso de diferenciação entre o humano e o divino”. Mauro P. Meiches também, a partir de Ricoeur, Vernant e outros importantes helenistas, coloca que, na tragédia, uma justiça divina entra em crise. Afirma que “a teologia trágica fala de uma indistinção entre o divino e o diabólico”, aquilo que causa erro no homem tem origem divina, mas tem de passar pela fraqueza humana para se fazer ato. $\mathrm{O}$ ato acaba sendo visto como fruto de uma possessão. Essa teologia passa por um processo de individualização de suas figuras antes indistintas. Apolo e Zeus são deuses individualizados, o que não acontece com as Fúrias.

Gláucia Dunley busca estabelecer uma diferença entre a tragédia e o trágico a tragédia teria a ver com a questão do excesso e o trágico com uma interrogação sobre o desejo.

Para Mauro P. Meiches, o trágico tem sua manifestação maior na tragédia grega que teria estetizado uma experiência que nos acompanha até hoje. Experiência da transitoriedade, experiência da transformação, experiência da dor. Por isso, "o trágico, como categoria estética ou princípio filosófico, ultrapassa sua concretização na tragédia grega, podendo manifestar-se em todo tipo de linguagem artística e filosófica”. Aqui o autor formula sua tese principal: não há conhecimento sem dor "o trágico estaria ligado intrinsecamente a esse trabalho de conhecimento que passa inexoravelmente pela dor. Sentir não seria suficiente para definir uma condição trágica; é preciso também sabê-la trágica”. Daí também a analogia com o processo analítico. A ambivalência que caracteriza a tragédia, a dor como fruto do conhecimento, esses elementos fazem com que o estudo do trágico enriqueça a compreensão da clínica psicanalítica. É como se o estudo da tragédia permitisse nomear momentos de qualquer processo de autoconhecimento. Mauro P. Meiches tem como centro de indagação não apenas o herói trágico. Interessantíssima é sua idéia de tomar a cidade como um outro analógico para a idéia de sujeito psíquico. Penso existir aqui um fecundo campo de trabalho e venho apontando isso em alguns trabalhos meus: a leitura da cidade como permeada de quiasmas pulsionais (vide "Escrituras Urbanas”, in Leituras de psicanálise, estéticas da exclusão, org. Maria R. C. Pereira, Campinas: Mercado de Letras). A cidade vai acolher o selvagem, trabalhar com a desmedida. O texto trágico vai ser um dos instrumentos ao constituir metáforas para a vida política, e ao desenhar "o traçado do cultural”.

Para Mauro P. Meiches "a via trágica mantém desperto um interesse pelo tema da dor, que não começou na tragédia, mas diz respeito ao cidadão”. E a experiência dolorosa forja a transformação.

Haveria aqui uma apologia da dor? Não estaríamosi sujeitos a uma certa concepção do processo analítico como mergulho na negatividade de uma falta constituinte do humano? 
São esclarecedoras a respeito as citações de Nicole Loraux, trazidas pelo autor: "O trágico tem sempre cumplicidade com o que chamarei não tanto de apolítico (o que supõe simplesmente o desengajamento e o desinteresse), mas de antipolítico - tudo aquilo que a cidade recusa ...” Os conteúdos recônditos da alma, em uma perspectiva trágica, também são determinados por vontades divinas, e é para lutar contra essa submissão que a tragédia acontece na vida cultural grega. Para Mauro Meiches, "o que o antipolítico aponta é a possível existência de um inamovível do homem, um lugar genérico que sempre estará em conflito com as formas da vida em sociedade” A pulsão de morte ou o pulsional. Gláucia Dunley e Mauro P. Meiches encontram-se apontando o trágico do mal-estar na civilização.

A dor de um destino do mal-estar. A dor deste inamovível da pulsão de morte, daquilo que não tem representação e insiste. Só a dor não caracteriza o trágico. O trágico implica sempre conflito entre duas ordens de coisas: há uma contradição que não se resolve. Mauro lembra Goethe para quem todo o trágico se baseia numa contradição irreconciliável.

Hoje, para Mauro P. Meiches, o trágico se faz presente em várias manifestações que exibem a contradição entre o que cabe nas "teias da representação" e o que permanece "não metabolizado, não apaziguado ainda”.

Cabe aqui uma observação sobre o percurso de Mauro P. Meiches: no seu trabalho sobre José Celso Martinez Corrêa, o tema é a vida pulsional como movimento, turbulência que precisa ser apaziguada. São vetores que falam do desejo. A sublimação também teria a ver com movimentos do desejo e toda a arte teria nascimento em movimentos pulsionais. Para entender o processo de criação do Teatro Oficina, Mauro indaga-se: "e se, numa exposição clara da velocidade e aspiração dos impulsos desejantes que detonam seu nascimento, as obras de arte passassem a acontecer numa espécie de curto-circuito em relação aos seus projetos iniciais? Na dinâmica entre estas duas vertentes de velocidade e possibilidade tão diferentes, dar-se-ia um descompasso, um hiato, onde o circuito de um trajeto poderia repentinamente se fechar, criando um ponto observável, minimamente consistente, índice que dá notícias do projeto. Este circuito menor, curto-circuito, descarregaria uma urgência impossível de continuar contida por um adiamento sem fim da execução do anseio inicial. Só que, com sua repetição, a coleção desses circuitos menores passaria a constituir uma obra em si, que pode ser historiada e interpretada em seu tempo de duração e composição de linguagem”. Mauro P. Meiches fala da transformação dos sujeitos criadores em uma espécie de pulsão ambulante.

Do movimento de José Celso ao inamovível de uma temporalidade mítica. Mundos possíveis, leituras possíveis, focos que se justapõem, repetindo o movimento trágico de contradições inevitáveis e que ressurgem infinitamente. É como se Mauro P. Meiches estivesse mais nietzschiano no momento em que elaborou seu trabalho sobre o Teatro Oficina: deixa-se tomar pela vertigem embriagadora de 
um teatro que se propõe dionisíaco. Agora, quer pensar sua clínica e pensa o trágico como fazendo parte da análise, quer pensar as transformações identificatórias que nos estruturam. Lembra Jô Gondar para quem a experiência trágica é aquela que se deixa marcar pelo tempo do acaso, um tempo de uma não ligação, tempo da pulsão no que diz respeito ao silêncio, à repetição, à estranheza. Não ligação, não representacional, buscando o mito para poder nomear o terror.

Para Mauro P. Meiches, o tempo que chama trágico é aquele que demanda o desejo de um diálogo forte com um passado "mítico". Essa demanda vem de um novo que não consegue ser ainda nomeado e quer saber o que, do passado, reverbera de um jeito desconfortável no presente.

A partir de minucioso estudo de Aristóteles, o autor vai aprofundando a analogia com a psicanálise considerando que não por acaso muitas metáforas psicanalíticas se dão a partir do teatro, em especial de um teatro trágico. Afirma: "De fato, o cidadão ateniense, ao aceitar participar de um ato como este, permitia que uma dimensão sensual, viva, musical, tomasse a condução de seus sentidos, que, 'desgovernados' por esta influência, passavam a governar a reflexão, pelo menos por um tempo". A psicanálise proporia algo semelhante: "que um teatro tenha lugar por um tempo; que nele se faça a representação mimética por meio da transferência de modos de ação (e também de afetos). Um teatro do inconsciente se reencena, desligado em parte de seu lastro histórico cronológico, como no mito”. Em meu doutorado, trabalhei Freud e Stanislavski e o título de um dos capítulos é: "O teatro instaura sempre um tempo do calendário, na medida em que é sempre um aqui-e-agora absoluto. Assim sendo, a repetição é sempre a ritualização de um mito”. O tempo ganha contornos de história, deixa de ser um tempo homogêneo escorrendo pelo relógio. Tanto no trabalho analítico como no teatro. O aqui-e-agora da sessão e o aqui-e-agora de cada espetáculo teatral.

Mauro P. Meiches fala em conhecimento, possibilidade de reflexão. Não haveria aqui uma proximidade com as teses de Habermas, ou seja, uma crença na possibilidade do conhecimento dar conta do que nos escapa? Claro que a tese é de que aí se instaura o trágico, onde o conhecimento não consegue dar conta. Mas a questão fica focada, aristotelicamente, na dor do conhecimento. Há uma crença de que a representação opere transformações dos afetos, possibilitando o contato com coisas antes intocáveis. Isso aconteceria por meio da sensualidade estética: existe primeiro um arrebatamento que depois convence ou faz refletir. Há uma passagem do mítico para o estético, pois olhar o mito com olhos de cidadão indica uma mudança de posição: está implícita aqui uma depuração intelectual que concerne um sentido de racionalidade crescente. Não há como não lembrar Cassirer e o trabalho de Isaías Melsohn. Segundo Isaías Melsohn (Isaías Melsohn: a psicanálise e a vida, Sister, B. e Taffarel, M., São Paulo: Escuta), Cassirer nos instrumenta como psicanalistas ao descrever formas simbólicas não-discursivas: "são modos de 
constituição e de percepção não organizados lógico-gramaticalmente, e seu sentido se manifesta diretamente na sua expressão”. Ou seja, o seu sentido não deve ser buscado numa outra ordem de linguagem por trás da expressão. Isaías Melsohn pensa que o mito foi banido como objeto de pensamento no florescimento da filosofia grega e que só bastante recentemente é que se restaurou o irracional do mítico, “do emocional, em sua autonomia como forma de pensar e objeto de estudo". Para Isaías, "a vida emocional, da mesma forma que o sentido da arte, é heterogênea ao discurso”. O artista vai descobrir o valor da expressividade, ou seja, vai resgatar o que é pura vivência afetiva no mito, momento de fusão eu-mundo.

Momento ansiado por Nietzsche, também presente no trabalho de Mauro P. Meiches. Contrariamente a Aristóteles, Nietzsche, na "Tentativa de Autocrítica” que introduz $O$ nascimento da tragédia, afirma que "a cientificidade é apenas um temor e uma escapatória para o pessimismo". O filósofo afirma aí a necessidade de voltar-se para a arte, pois "o problema da ciência não pode ser reconhecido no terreno da ciência”. Em Nietzsche, o coro satírico aparece como prova de que a vida é "indestrutivelmente poderosa e cheia de alegria” e que "o coro dos seres naturais, que vivem, por assim dizer, indestrutíveis, por trás de toda civilização, e que, a despeito de toda mudança de gerações e das vicissitudes das história dos povos, permanecem perenemente os mesmos. (...) O êxtase do estado dionisíaco, com sua aniquilação das usuais barreiras e limites da existência, contém, enquanto dura, um elemento letárgico, no qual emerge toda vivência pessoal do passado". Para Nietzsche o coro da tragédia nasce dos entusiasmados servidores de Dionísio, que se vêem a si próprios como gênios da natureza, como sátiros. O coro é a imitação desse processo natural.

Fazendo a apologia da ilusão, brindando a vida, resgatando a religiosidade do mítico, Nietzsche assustou Freud. E ainda nos assusta e encanta, como psicanalistas. Mesmo a noção de força, de potência, não pode simplesmente ser "traduzida" para o conceito freudiano de pulsão. É rica a polêmica respeitosa que Mauro P. Meiches faz com o nietzschiano Alfredo Naffah.

O fato é que Mauro P. Meiches segue à risca a indicação de Nietzsche: é preciso ir à arte para poder refletir sobre a nossa clínica. Contra qualquer psicanálise aplicada, Mauro vai ao teatro para melhor se instrumentar na compreensão de seus pacientes. O seu trabalho é entremeado pela exposição de casos clínicos nos quais busca a apreensão do trágico. Pena que a riqueza da discussão teórica ofusque a exposição da clínica, que aparece quase que somente a título de ilustração, correndo o risco, aí sim, de ser apenas uma aplicação de sua exposição teórica.

De qualquer modo, o trabalho vivo de Mauro P. Meiches obriga a repensar nossa atividade como psicanalistas, mostrando como temos de nos deixar levar pelos ventos da criação poética para poder desenhar, com traços delicados e fluídos, nossa clínica. 